\title{
Arte verbal e música na língua Gavião de Rondônia: metodologia para estudar e documentar a fala tocada com instrumentos musicais
}

\section{Verbal art and music in the Gavião language of Rondônia: methodology for the study and the documentation of speech played on musical instruments}

\author{
Julien Meyer', Denny Moore \\ 'Museu Paraense Emílio Goeldi/MCTI. Belém, Pará, Brasil
}

\begin{abstract}
Resumo: Em uma língua com tom e prolongamento distintivos, como Gavião de Rondônia, a primeira questão sobre a fala tocada com instrumentos musicais é a relação entre as melodias e a fonologia suprassegmental das palavras correspondentes na fala cantada e na fala normal. A forma cantada serve para aprender e explicar os toques musicais. Ela é influenciada pelos recursos fonológicos da forma falada e pelos recursos musicais da forma instrumental, sendo intermediária entre as duas. Esta arte é executada com vários instrumentos musicais tradicionais na cultura Gavião de Rondônia. O papel da fala cantada instrumental é artístico, para acompanhar festas, e também prático, para ajudar a manter o patrimônio oral de uma cultura não escrita. Esta prática representa um patrimônio sociocultural do substrato tradicional das culturas da Amazônia, pouco estudado e ameaçado de extinção. Na Terra Indígena Igarapé Lourdes, usamos uma metodologia original para documentar este fenômeno nos instrumentos musicais identificados como 'falantes' ou 'cantantes' pelos colaboradores Gavião. As sessões de gravação e de transcrição necessárias para esse tipo de trabalho foram explicadas aqui. Elas revelaram a relação de iconicidade acústica que existe entre as palavras e a música. A análise linguística permite entender a natureza fonética e fonológica da iconicidade.
\end{abstract}

Palavras-chave: Gavião de Rondônia. Música. Instrumentos musicais. Fala instrumental. Fala cantada. Tom da fala.

Abstract: In a language with distinctive tone and length, such as Gavião of Rondônia, the first question about speech played by musical instruments is the relation between the melodies and the super-segmental phonology of the corresponding words in sung speech and in normal speech. The sung speech is useful for learning and explaining the musical notes. It is influenced by the phonological possibilities of the spoken form and by the musical possibilities of the instrumental form, being intermediate between the two. This art is performed with various Gavião traditional musical instruments. The role of the instrumental sung speech is artistic and also practical, to help to maintain the oral heritage. This practice represents a little-studied and threatened cultural heritage of the traditional substratum of the cultures of Amazonia. On the Indigenous Reserve Igarapé Lourdes we used an original methodology to document this phenomenon in the musical instruments which the Gavião collaborators identified as 'speaking' or 'singing'. The recording and transcription sessions necessary for this type of research will be explained here. They show the relation of acoustic iconicity which exists between the words and the music. Linguistic analysis makes it possible to understand the phonetic and phonological nature of the iconicity.

Keywords: Gavião of Rondônia. Music. Musical instruments. Instrumental speech. Sung speech. Phonological tones.

MEYER, Julien; MOORE, Denny. Arte verbal e música na língua Gavião de Rondônia: metodologia para estudar e documentar a fala tocada com instrumentos musicais. Boletim do Museu Paraense Emílio Goeldi. Ciências Humanas, v. 8, n. 2, p. 307-324, maio-ago. 2013. Autor para correspondência: Julien Meyer. Museu Paraense Emílio Goeldi/MCTI. Av. Perimetral, 1901. Terra Firme. Belém, PA, Brasil. Caixa Postal 399. CEP 66077-530 (julmeyer.lab@gmail.com).

Recebido em 26/06/2012

Aprovado em 03/06/2013

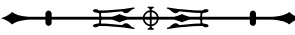




\section{INTRODUÇÃO}

\section{TOCAR, CANTAR, FALAR: ESTRUTURAS DE SOM EM COMUM}

Tocar instrumentos musicais e cantar são atividades independentes. De fato, cantos podem existir que não sejam acompanhados de música tocada e música tocada pode existir sem letras. Há várias possíveis relações entre os dois. Em várias culturas do mundo, há música tocada que tem um canto associado, mesmo se o canto e a música não são sempre produzidos juntos. Entre os Gavião de Rondônia, existem três tipos de instrumentos musicais, sempre tocados separadamente dos seus cantos associados. Os cantos são ensinados para facilitar a aprendizagem da música instrumental, mas os tocadores raramente os usam em outras ocasiões. Ouvindo as melodias tocadas, observadores ingênuos não desconfiam da relação que elas têm com as letras associadas, nem do fato de aspectos fonológicos das letras, como são faladas, normalmente serem refletidos nas melodias. Na verdade, essas melodias instrumentais são, por grande parte, baseadas na estrutura da linguagem, e a percepção dos Gavião é a de que os instrumentos estão falando ou, mais exatamente, que estão expressando a forma cantada da fala. Daí vem a ideia de instrumentos 'cantantes'.

\section{INSTRUMENTOS QUE CANTAM NO MUNDO}

Presente em várias partes do mundo, o fenômeno de instrumentos que 'cantam' (imitam aspectos da fonologia das palavras associadas à música) representa uma arte verbal de instrumentos musicais tradicionais (flautas, tambores, arcos de boca, tabocas de bambu etc.). Ele é pouco conhecido na América Latina, embora a região amazônica seja uma das raras regiões com grande diversidade de línguas indígenas ainda expressas dessa maneira. Algumas publicações, por exemplo, indicam que esta particularidade foi observada antigamente na região (Whiffen, 1915; Izikovitz, 1935), enquanto outras referências mais recentes mostram que ela ainda existe em formas diferentes pelo menos nas culturas Bora (Thiesen, 1969; Meyer et al., 2012), Cinta Larga (Ermel, 2004), Gavião (Mindlin et al., 2001; Ermel, 2001)1, Kuikuro (Franchetto e Montagnani, 2011), Pirahã (Everett, 1983), Wakuenai (Hill, 1993) e Aikanã².

Considerando-se outras partes do mundo, o modo cantado dos instrumentos musicais foi principalmente estudado no oeste da África e é reconhecido como uma das características importantes do patrimônio musical das culturas desta região (Carrington, 1949; Sebeok e Umiker-Sebeok, 1976; Nketia, 1976; Locke e Agbeli, 1981; Zemp, 2004). Esse fenômeno linguístico-musical foi também indicado como bastante comum no sudeste da Ásia, com vários tipos de instrumentos (Stern, 1957; Catlin, 1982; Poss, 2005; Meyer, 2007), e em Papua Nova Guiné (Niles, 2010). A noção de modo cantado dos instrumentos musicais foi pela primeira vez definida por Nketia (1976) para distinguir, na cultura Akan, da África, os toques de tambores usados para telecomunicação (emulando a fala normal), dos toques ligados a cantos (emulando a fala cantada). Essa distinção entre modo falante e modo cantante dos tambores existe também na Amazônia, na cultura Bora (Thiesen, 1969). Para os Gavião de Rondônia, uma distinção equivalente existe entre a fala assoviada, que serve para emular a fala normal no caso de comunicação à distância, e a fala instrumental, que emula canções apresentadas neste estudo.

1 Consultar ainda: DENTEL, Laure; MEYER, Julien; DA SILVA SEBIROP, Josias; SEBIROP GAVIÃO, Xipiabit. "Arte verbal Gavião das tabocas Totoráp". Belém: Museu Paraense Emílio Goeldi, 2010 (vídeo de documentação); MEYER, Julien; DENTEL, Laure; SEBIROP GAVIÃO, Xipiabit. "Canções Gavião". Belém: Museu Paraense Emílio Goeldi, 2010 (vídeo de documentação); MEYER, Julien; DENTEL, Laure; DA SILVA SEBIROP, Josias; SEBIROP GAVIÃO, Xipiabit. "As flautas Kotiráp e os arcos Iridináp, arte verbal Gavião". Belém: Museu Paraense Emílio Goeldi, 2010 (vídeo de documentação).

2 Consultar VAN DER VOORT, Hein. “A Música Sagrada dos Aikanã”. Belém: Museu Paraense Emílio Goeldi, 2010 (vídeo de documentação).

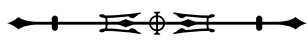




\section{ESTUDOS E METODOLOGIA}

Embora os trabalhos anteriormente citados representem um avanço importante, ainda são poucos, e muitas perguntas permanecem sem resposta sobre o funcionamento linguístico desses sistemas de fala. No caso das línguas amazônicas, quase não há estudos sistemáticos de linguística científica sobre o tema. Isso já é um fato suficiente para justificar o desenvolvimento de uma iniciativa de documentação da fala cantada instrumental. Mas outro importante fator é que, em geral, formas instrumentais da fala são perdidas antes das formas envolvendo unicamente a voz. No caso dos Gavião de Rondônia, essa situação é preocupante, uma vez que é sintomática a ameaça que pesa sobre todo o patrimônio oral.

Frente à baixa taxa de transmissão intergeracional, os Gavião que se preocupam com a manutenção da cultura tradicional acharam importante ter assessoria científica para a salvaguarda. A capacidade de tocar músicas que imitam os sons do seu canto associado exige um conhecimento complexo, envolvendo o controle de várias técnicas diferentes. Por exemplo, a manufatura dos instrumentos, a aprendizagem de um vasto repertório de canções ou o toque de notas musicais em correspondência com palavras. Às vezes, implica também a coordenação entre diferentes pessoas envolvidas na música ou a realização simultânea de danças pelos tocadores no contexto de uma festa. Além disso, os textos fazem regularmente referência à cosmogonia tradicional Gavião e à relação entre o povo e o meio ambiente amazônico; participando da sua atuação viva no dia a dia. Por causa disso, essas práticas culturais sofrem a pressão invasiva e destrutiva de religiões importadas recentemente, que as depreciam e, às vezes, as proíbem. Na substituição dos textos das crenças tradicionais por outros textos, as religiões não nativas eliminam formas tradicionais das artes indígenas, além da visão mítica tradicional do mundo natural e sobrenatural do povo.

Como parte da resposta a essa urgência, tanto científica quanto cultural, o presente artigo descreve o processo de documentação dos três principais instrumentos musicais identificados como 'cantantes' pelos colaboradores Gavião. A metodologia específica necessária para estudar estes fenômenos foi desenvolvida em várias aldeias na Terra Indígena Igarapé Lourdes (Rondônia). Todas as suas etapas são explicadas aqui, desde a identificação dos instrumentos envolvidos até o armazenamento dos dados em um acervo digital. As etapas são passíveis de réplica e adaptação a outras culturas com práticas semelhantes. Além disso, a última parte do artigo dá enfoque particular à relação de semelhança acústica que existe entre a melodia musical e as palavras correspondentes no seu canto associado, ou mesmo na fala normal. A análise linguística é importante para se entender a natureza fonética e fonológica dessa relação icônica, que é uma das bases da criatividade e da memória musical do povo Gavião.

\section{METODOLOGIA}

\section{LEVANTAMENTO INICIAL}

Devido às particularidades do modo cantado dos instrumentos musicais Gavião, concebemos uma metodologia original (como ilustrado na Tabela 1), que permite registrar todos os aspectos necessários para documentar esse fenômeno. Cada etapa foi observada e gravada em vídeo e/ou áudio. O primeiro passo, após apresentar o projeto, foi discutir, com as pessoas mais tradicionais, as formas instrumentais da língua. Fizemos perguntas como: quem faz, como, quando, onde e em que contexto. Organizamos sessões de entrevistas com vários informantes em várias aldeias para identificar e gravar um repertório mais amplo possível de canções.

Identificamos três tipos de instrumentos diferentes, quase exclusivamente usados para cantar:

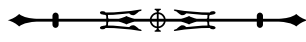


- Uma flauta de bambu, chamada Kotiráp [kōt Jīrāp] (Figura 1);

- Uma dupla de arcos de boca, chamada Iridináp [ïrīiñnām] (Figura 2);

- Um conjunto de três tabocas de bambu de tipo clarinete amazonense, chamado Totoráp [tōtōrāp] e tocado por três pessoas simultaneamente (Figura 3).

Tabela 1. Etapas da metodologia.

\begin{tabular}{c|l}
\hline Etapa & \multicolumn{1}{c}{ Atividade de pesquisa/documentação } \\
\hline 1 & $\begin{array}{l}\text { Censo preliminar e exploração dos objetivos do projeto com os colaboradores indígenas, capacitação na aldeia } \\
\text { em gravação de vídeo e áudio }\end{array}$ \\
\hline 3 & $\begin{array}{l}\text { Documentação da manufatura e do ajuste dos instrumentos } \\
\text { fárias sessões de gravação para cada canção, focalizando sucessivamente as três maneiras diferentes de produção: a } \\
\text { características acústicas de cada instrumento }\end{array}$ \\
\hline 4 & $\begin{array}{l}\text { Transcrição e tradução da forma cantada e falada, seguindo a metodologia da linguística científica (início no campo, } \\
\text { continuação com colaboradores indígenas convidados na cidade) }\end{array}$ \\
\hline 5 & Edição preliminar dos vídeos já gravados \\
\hline 7 & Capacitação em edição de vídeo e áudio (DVDs e CDs, incluindo capas) \\
\hline 8 & Correção dos vídeos com professores de escola e outros colaboradores \\
\hline 9 & Edição final de produtos oriundos do projeto (CDs, DVDs) e divulgação nas comunidades \\
\hline 10 & Depósito dos CDs e DVDs em um acervo digital nacional, com disponibilidade permanente para a comunidade indígena \\
\hline Análise detalhada (acústica, fonológica e musicológica) para determinar os padrões das três formas (instrumental, \\
cantada e falada) e verificar as semelhanças e divergências entre estas formas
\end{tabular}

Como vamos ver adiante, dois desses instrumentos produzem também melodias que são associadas a sílabas sem significado, cantadas para efeito rítmico (ver tópico "Repertório e alguns exemplos de canções"). Além disso, há entre os Gavião outros instrumentos que tocam peças musicais sem correspondência na fala ${ }^{3}$ e outros gêneros de cantos não associados a instrumentos musicais ${ }^{4}$.

Cinco aldeias foram visitadas durante quatro viagens de campo, realizadas entre junho de 2009 e julho de 2011. Esse primeiro censo mostrou que os arcos Iridináp eram exclusivamente femininos, tocados tradicionalmente por meninas na idade de se casar (tradicionalmente ao redor de 15 anos). Atualmente, as mulheres ainda capazes de tocar e ensinar essa arte às meninas são poucas e todas têm mais de 60 anos. Além disso, não há meninas que saibam tocar o instrumento. No caso da flauta Kotiráp e das tabocas Totoráp, a maioria dos bons tocadores tem 45 anos ou mais. São instrumentos exclusivamente masculinos, e poucos jovens têm a prática de tocá-los.

Devido ao interesse indígena em documentar e manter as suas práticas musicais, treinamos alguns membros da comunidade em gravação de áudio e vídeo. O trabalho de gravação foi colaborativo.

3 Consultar MEYER, Julien; GAVIÃO, Emílio. "Ãberáv e Goyã dorléhj”. Belém: Museu Paraense Emílio Goeldi, 2011 (vídeo de documentação); MEYER, Julien; GAVIÃO, Emílio. "Duas flautas Gavião”. Belém: Museu Paraense Emílio Goeldi, 2011 (vídeo de documentação).

4 Consultar MEYER, Julien; DENTEL, Laure; SEBIROP GAVIÃO, Xipiabit. "Canções Gavião". Belém: Museu Paraense Emílio Goeldi, 2010 (vídeo de documentação).

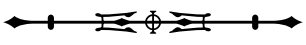




\section{DOCUMENTAÇÃO DA MANUFATURA DOS INSTRUMENTOS}

A segunda etapa consistiu em seguir e documentar com vídeo os processos de preparação dos instrumentos musicais: coleta do material no mato, manufatura e ajuste das notas. Esses instrumentos podem ser guardados vários meses após a confecção, mas as suas qualidades sonoras são melhores com madeira cortada recentemente. A única parte que deve ser obrigatoriamente confeccionada e ajustada na hora de tocar é a palheta das tabocas (Figura 3) porque ela só é eficiente como fonte acústica se o bambu estiver ainda verde.

\section{DOCUMENTAÇÃO DAS TRÊS FORMAS: TOCADA, CANTADA E FALADA}

$\mathrm{Na}$ terceira etapa, nossa metodologia requereu a documentação de uma música e seu canto associado de várias maneiras, cada uma focalizando um aspecto diferente. Primeiro, a música instrumental foi tocada, gravada e descrita no seu contexto natural ou, pelo menos, em uma simulação do contexto natural. Segundo, o canto associado, sem a música instrumental, foi cantado, gravado, transcrito e descrito etnograficamente. Terceiro, as letras do canto foram faladas (não cantadas) em voz normal, sendo gravadas e transcritas como textos são transcritos na metodologia da linguística descritiva científica.

Para fazer esta transcrição, é necessário já ter um estudo razoavelmente completo da língua e ter a ajuda de um consultor indígena para pronunciar e traduzir as palavras, responder a perguntas analíticas e ajudar a identificar aspectos da linguagem do canto, que são diferentes do uso normal.

Um problema desta etapa é a dificuldade de suprir o impulso de cantar as letras ao invés de falá-las. Outra dificuldade interessante é a de identificar e entender formas arcaicas ou raras nas letras, que são comuns nos cantos antigos. Essas gravações e transcrições revelaram como opera a iconicidade acústica entre palavras e música, como será detalhado na próxima seção do artigo.

Durante as gravações de documentação e sua descrição, informações detalhadas foram coletadas sobre cada instrumento: contexto de uso, repertório e características acústicas. Como deve ser feito em toda documentação, as informações relevantes sobre os eventos gravados foram anotadas (localização, situação, participantes, data, hora etc.) com a ajuda de falantes nativos. A transcrição começou na aldeia e foi revisada posteriormente em Belém, Pará. Além disso, dois colaboradores Gavião (incluindo um professor indígena) foram convidados para ir a Belém para verificar a transcrição e a tradução das palavras das canções.

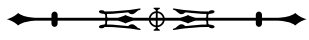




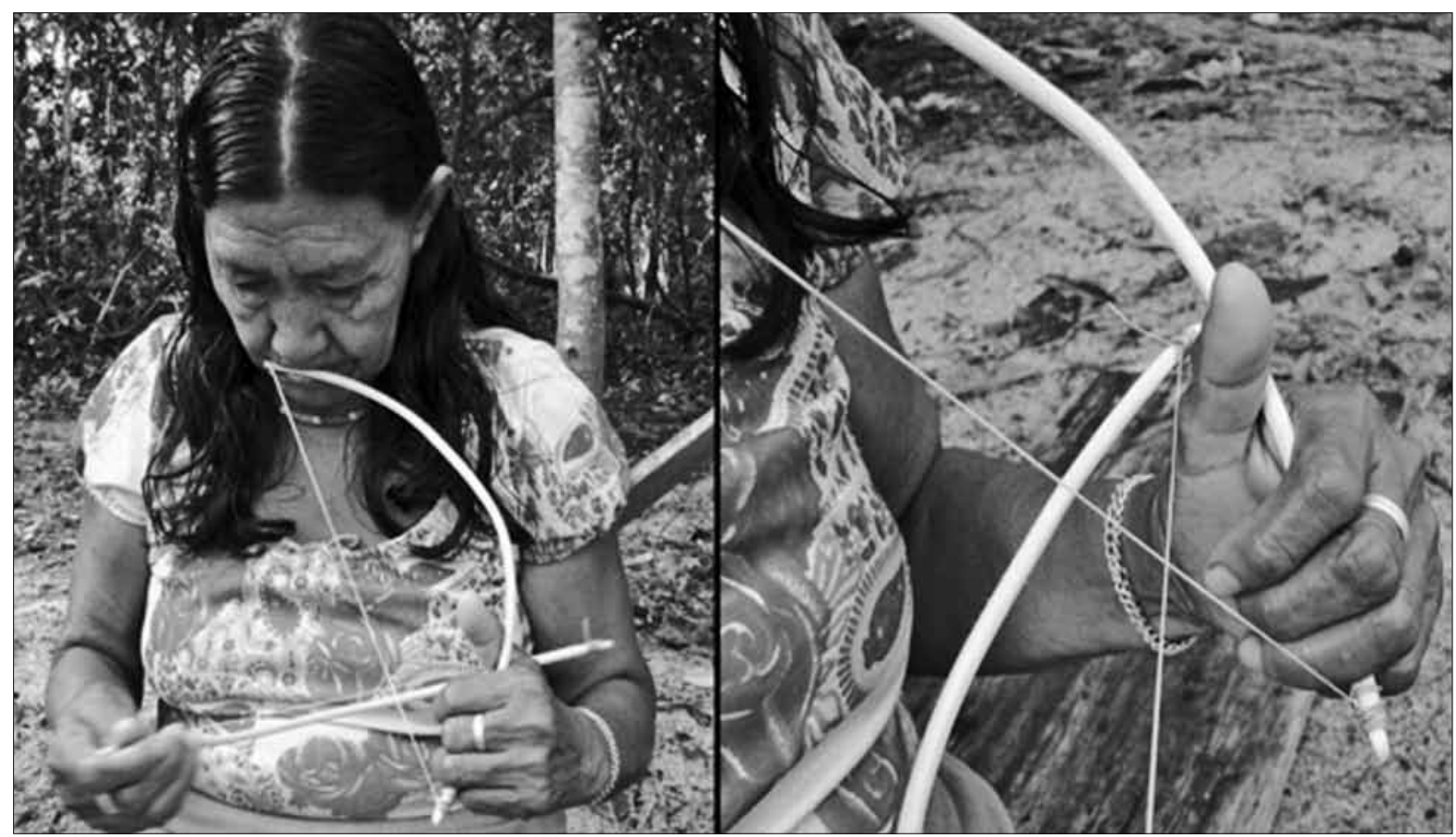

Figura 2. Arcos Iridináp. Fotos: Julien Meyer.

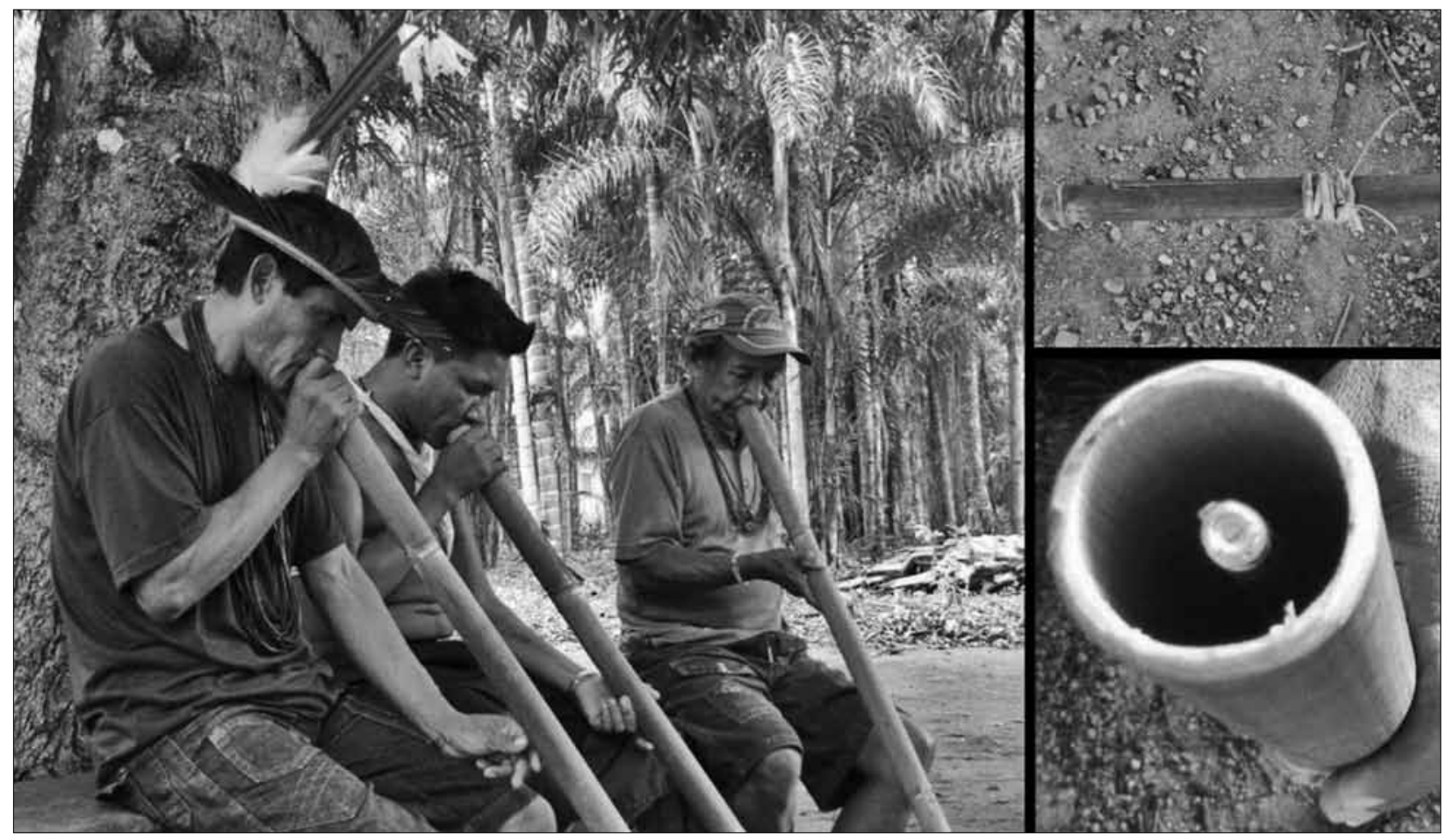

Figura 3. O instrumento Totoráp é composto de três tabocas de bambu, cada uma tocada por uma pessoa diferente. Fotos: Julien Meyer.

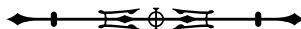




\section{PRODUÇÃO DE CDS E DVDS, CAPACITAÇÃO DA COMUNIDADE EM DOCUMENTAÇÃO E DEPÓSITO EM UM ACERVO DIGITAL NACIONAL}

Um dos principais objetivos da nossa metodologia consistiu na produção de DVDs de vídeo e CDs de áudio, valorizando, de maneira didática, este patrimônio oral, com capacitação de alguns jovens indígenas nas técnicas de gravação e edição. Esta etapa é popular nas aldeias porque visa o fortalecimento das práticas culturais e motiva ações de documentação pelas próprias comunidades onde sobrevive o conhecimento tradicional.

Para dar suporte à iniciativa local, dois gravadores digitais de áudio foram doados à comunidade, sob a responsabilidade de um participante Gavião do projeto e do presidente de uma associação Gavião.

O interesse conjunto atual dos índios e dos pesquisadores pelas técnicas de documentação se justifica porque elas ajudam a construir uma ponte moderna entre gerações, quando o enfoque está nas partes mais tradicionais das culturas. Além disso, com o retorno da documentação à comunidade, observamos que as crianças e os jovens que veem prestigiados esses aspectos da sua cultura em tais meios passam a ter maior interesse por eles. Por exemplo, as meninas e os meninos de uma aldeia aprenderam algumas das canções após assistirem aos DVDs várias vezes. Esses resultados não pretendem substituir a transmissão tradicional, mas incentivá-la.

Um último aspecto dessa documentação é o fato de que ela é depositada e guardada em um acervo digital nacional permanente, onde sempre estará disponível às comunidades indígenas. É uma contribuição à memória cultural e linguística desses grupos, importante para a revitalização da língua e cultura.

\section{ALGUNS RESULTADOS}

\section{REPERTÓRIO E ALGUNS EXEMPLOS DE CANÇÕES}

O aspecto mais surpreendente da música tocada com esses instrumentos é que os Gavião indicam espontaneamente que ela tem um significado. Com perguntas específicas, é possível ter mais detalhes porque não há nenhum segredo sobre o fenômeno. Geralmente, os tocadores argumentam que os instrumentos dizem palavras. Se insistir, muitas vezes eles primeiro relatam a história contada pelas letras da música. Outras vezes, eles vão cantá-las. A versão cantada é a chave da técnica instrumental, porque é exatamente ela que serve de modelo para a música. Ela deixa mais claro o papel linguístico do estudo desse fenômeno para entender como a língua influencia a música por meio da correspondência de cada palavra com as notas e os ritmos tocados.

Aqui estão alguns exemplos de canções. Elas são curtas e repetidas várias vezes em uma sessão musical. Cada instrumento tem um repertório dedicado e usa algumas palavras antigas (em itálico nos textos (a), (b) e (c) a seguir). Ademais, as canções de Totoráp e Iridináp intercalam melodias rítmicas instrumentais sem significado (por exemplo, iriri, toy péréré, sết sết, o sết o sết) entre frases cantadas. Essa característica nunca foi encontrada nas canções da flauta Kotiráp. Existem outros processos rítmicos e estéticos ligados à melodia tonal que serão expostos no final do artigo.

\section{a) Arcos Iridináp}

A melodia Iridináp que todo mundo conhece é a seguinte:

aấ bó õbút mága $(2 x)$

iriri iriri este é meu

(ritmo instrumental)

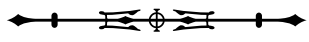


aấ bó alimé akút mága $(2 x)$

iriri iriri

aấ bó ikốlo akút mága $(2 x)$

iriri iriri este é bom caçador de macaco preto

(ritmo instrumental)

este é bom caçador de gavião

(ritmo instrumental)

Às vezes, a melodia é associada a outra frase, que se intercala entre duas repetições da estrofe precedente:

amapit atíní atí mága ốgay

iriri iriri essa mulher tem ciúme de deixar seu filho comigo

(ritmo instrumental)

Outras canções fazem referência de maneira sutil ao prestígio do caçador, como essa:
toy péréré toy péréré
ẽbéré boráàt kỗòp ma' á
(ritmo instrumental)
toy péréré toy péréré
papá busca pó de remédio para a caça, tio
(ritmo instrumental)

b) Flauta Kotiráp

A flauta Kotiráp fala frequentemente de amor e casamento:

ốgali atí mápit bósara kî káre béá (2x) vou deitar com a filha dela, de novo

õot bó mága citá ẽmápit táá atíá eu vou ficar com sua filha, senhora

aaná õóbiri biriás

agora, debaixo de mim

õot bó mága citá ẽmápit táá atíá

sou eu que vou ficar com sua filha, senhora

aaná õóbiri biriá

agora, debaixo de mim $^{6}$

É também comum que as palavras façam referência a um mito (contando aqui a essência do fim da domesticação da jiboia):
aajaay va teé bay póóy máà áleá $(2 x)$
jiboia comeu seu dono
abóta pérúup mábuúre káá
porque ele não acertou o veado para ele
aajaay va eénaá
assim a jiboia comeu
abóta pérúup mábuúre káá
porque ele não acertou o veado para ele
aajaay va eénaá
assim a jiboia comeu

\section{c) Clarinetes Totoráp}

Atualmente, a melodia Totoráp, a mais popular, faz referência ao evento histórico da colonização da terra Gavião.

Duas sílabas repetidas.

6 A mulher Gavião dorme em uma rede debaixo do seu marido.

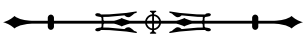




$\begin{array}{ll}\begin{array}{l}\text { aấ bó zaat máà pagátaa } \\ \text { o sết o sết }\end{array} & \begin{array}{l}\text { o branco invadiu nossa terra } \\ \text { (ritmo instrumental) }\end{array} \\ \text { aấ bó zaat máà pagátaa } & \text { aấ bó zaat máà pagátaa } \\ \text { o sết o sết } & \text { (ritmo instrumental) } \\ \text { zérék kît zérék kît } & \text { o branco, o branco } \\ \text { máà pagátaa } & \text { está invadindo } \\ \text { o sết o sết } & \text { (ritmo instrumental) } \\ \text { zérék kît zérék kîtt } & \text { o branco, o branco } \\ \text { máà pagátaa } & \text { está invadindo } \\ \text { o sết o sết } & \text { (ritmo instrumental) } \\ \text { ẽzáká ẽebií teé kay áleá } & \text { não tenha medo dele } \\ \text { zérék kît kay áleá } & \text { do branco } \\ \text { o sết o sết } & \text { (ritmo instrumental) } \\ \text { ẽzáká ẽebií teé kay áleá } & \text { não tenha medo dele } \\ \text { zérék kîtt kay áleá } & \text { do branco } \\ \text { o sết o sết } & \text { (ritmo instrumental) }\end{array}$

Os Totoráp podem também falar poeticamente para restituir um ambiente natural:

\begin{tabular}{|c|c|}
\hline $\begin{array}{l}\text { ikábiit ábi ká bi ká7 coliléèy mága } \\
\text { sết sết }\end{array}$ & $\begin{array}{l}\text { as andorinhas voam em cima do igarapé } \\
\text { (ritmo instrumental) }\end{array}$ \\
\hline ábiit ábi ká bi ká coliléèy mága & as andorinhas voam em cima do igarapé \\
\hline ét sết & (ritmo instrumental) \\
\hline blóp tî̀ zólốp tî̀ kat mága & tem um abacaxizal, um abacaxizal \\
\hline t sết & (ritmo instrumental) \\
\hline ólốp tî̀ zólốp tî̀ kat mága & tem um abacaxizal, um abacaxizal \\
\hline sết sết & (ritmo instrumental) \\
\hline ikááybîit ci tára & na margem do igarapé \\
\hline sết sết & (ritmo instrumental) \\
\hline ááybîit ci tára & na margem do igarapé \\
\hline t sết & (ritmo instrumental) \\
\hline
\end{tabular}

\section{CONTEXTO DE USO E TRANSMISSÃO}

Como foi mencionado, cada instrumento tem contextos dedicados de uso. Por exemplo, os arcos Iridináp das meninas servem exclusivamente para vincular mensagens tratando de amor (sedução, recusa e casamento). Usam-se em contextos privados, se tiver o namorado perto, ou durante algumas festas com todas as meninas tocando e dançando em fileira, cada uma com seu instrumento. A flauta Kotiráp serve para todo tipo de poesia; ela é bastante comum

\footnotetext{
7 Duas sílabas repetidas.
}

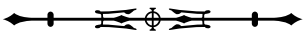


para a expressão de sentimentos de amizade, amor ou para a descrição de um evento marcante. Serve em contextos privados ou de festas, às vezes para responder aos arcos das meninas. Finalmente, as tabocas Totoráp servem para a animação de festas com bebidas, relatando eventos importantes da vida da comunidade, tais como cerimônias, guerra, impressões poéticas ou de caça.

Embora as crianças estejam ainda aprendendo sua língua materna, as formas instrumentais da língua são usadas cada vez menos. As palavras dessas canções fazem frequentemente referência a um conhecimento e às práticas tradicionais, que já são pouco conhecidas por grande parte da população Gavião devido à redução da frequência de eventos culturais tradicionais. Além disso, os colaboradores Gavião dizem que poucas canções instrumentais foram inventadas desde o tempo do contato, nas décadas 1940-1950. Dos três instrumentos documentados, só o Totoráp continua com certa vitalidade, pois é sistematicamente ligado a danças e festas.

Até o presente momento, apesar da cooperação excelente com a comunidade devido a uma relação de confiança na pesquisa da língua, iniciada nos anos 1970, só quatro canções com Iridináp foram encontradas e gravadas (com cinco informantes), oito canções com Kotiráp (com cinco informantes) e nove canções com Totoráp (com três grupos de três tocadores).

O censo está ainda em andamento, mas todos os informantes concordam em dizer que poucas canções permanecem para Iridináp e Kotiráp. Os mais velhos (acima de 70 anos), que possivelmente ainda conhecem outras canções, têm dificuldades em repassar o conhecimento porque não possuem mais a força de sopro ou a coordenação motora necessária para tocar. Como ficaram muito tempo sem tocar os instrumentos de sedução, é também difícil lembrarem-se das canções menos populares usadas no passado.

\section{CARACTERÍSTICAS ACÚSTICAS DOS TRÊS INSTRUMENTOS}

A música tocada com os instrumentos Totoráp, Kotiráp ou Iridináp é caracterizada acusticamente pelo timbre particular de cada instrumento (Figuras 4, 5 e 6), pela melodia das notas tocadas e pelos ritmos de frases musicais complexas intercaladas com ritmos simples.

Cada instrumento tem a sua assinatura acústica própria, caracterizada pelo timbre. A flauta Kotiráp é um instrumento de sopro com timbre simples, reduzido a um sinal sinusoidal na faixa de $500-900 \mathrm{~Hz}$ com as suas harmônicas (Figura 4). As tabocas Totoráp constituem um instrumento de sopro composto por três clarinetes monotonais, caracterizadas por sons harmônicos densos e complexos, com uma frequência fundamental na faixa de 100-200 Hz e suas harmônicas ímpares reforçadas (Figura 5). O Iridináp é um instrumento que - igual ao violino - é baseado no princípio de cordas friccionadas: a tocadora aplica três níveis de tensão a uma única corda friccionada com o outro arco (Figura 2). O resultado acústico é uma frequência fundamental de 200-350 Hz e várias harmônicas igualmente reforçadas (Figura 6). Como os três instrumentos são harmônicos, a altura de cada nota tocada em qualquer instrumento é definida pela sua frequência fundamental (F0). O atributo perceptual do F0, chamado de pitch, constitui uma entidade independente e paralela ao timbre na percepção humana (Schouten et al., 1962; Risset, 1968; Schwartz e Purves, 2004).

$\mathrm{Na}$ acústica musical, a forma da variação da amplitude chama-se 'envelope da onda'. Isso se refere ao gráfico da amplitude do sinal, que mostra a variação da amplitude como função do tempo. O gráfico das melodias tocadas por cada tipo de instrumento descrito aqui é semelhante ao gráfico dos enunciados do canto associado (e então do seu ritmo). A flauta Kotiráp e os arcos Iridináp tendem a reproduzir os contornos do gráfico de amplitude do canto associado, com as flautas sendo mais precisas nesse aspecto (Figuras 4 e 5). No caso do Totoráp, cada uma das três tabocas tem

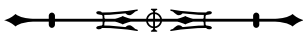




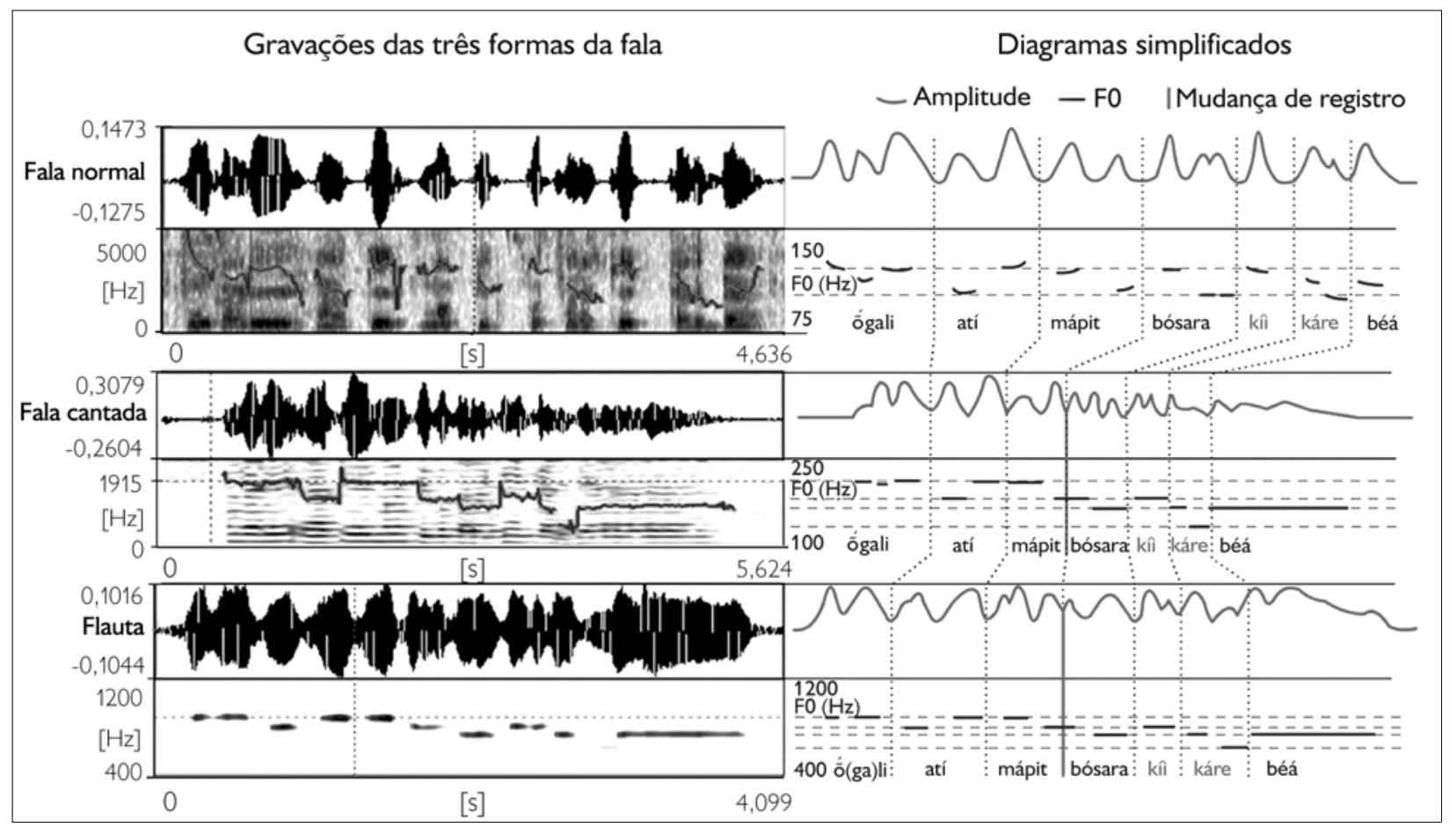

Figura 4. Extrato de flauta Kotiráp, ilustração completa da metodologia de análise.

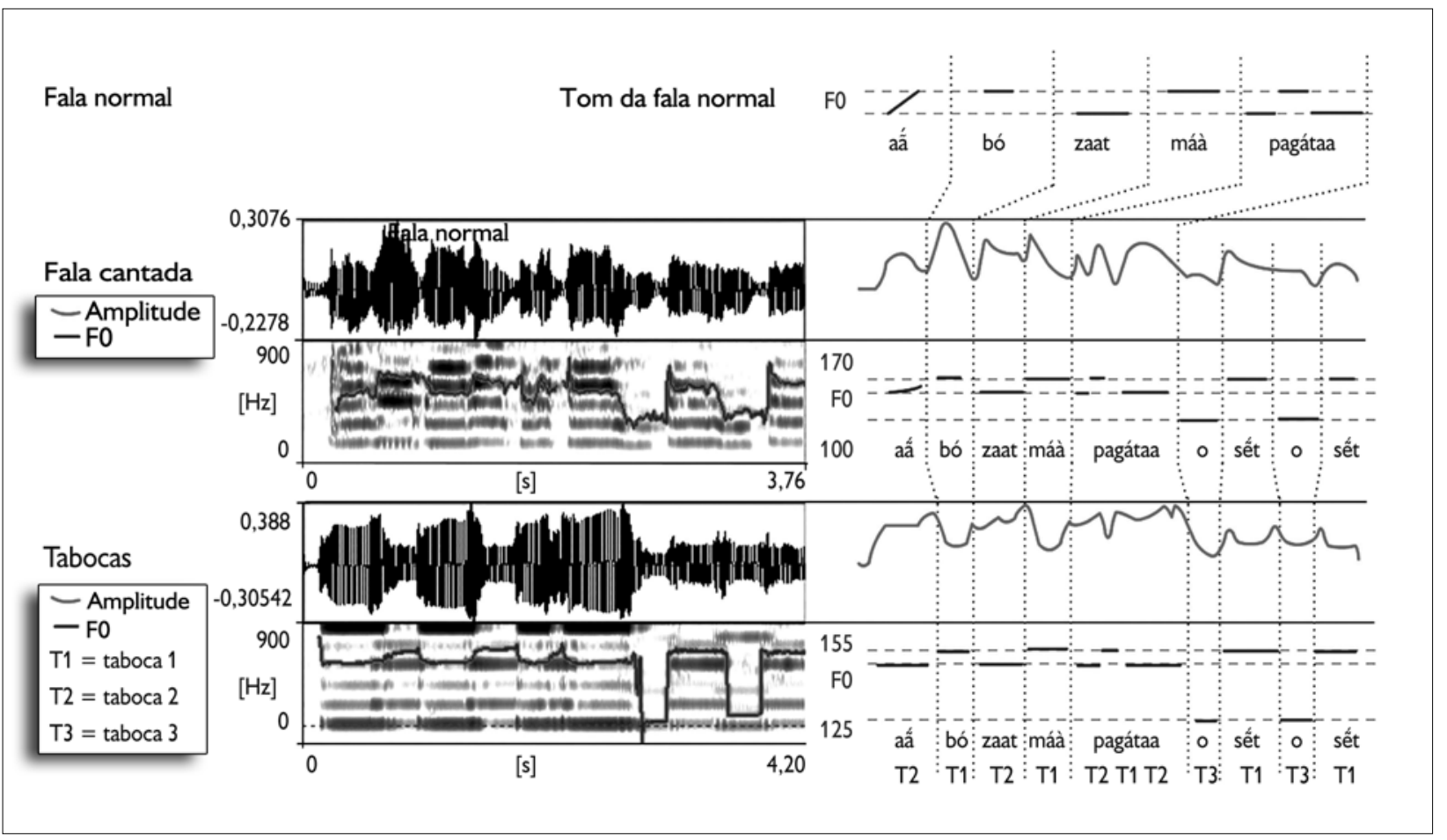

Figura 5. Extrato de tabocas Totoráp. 


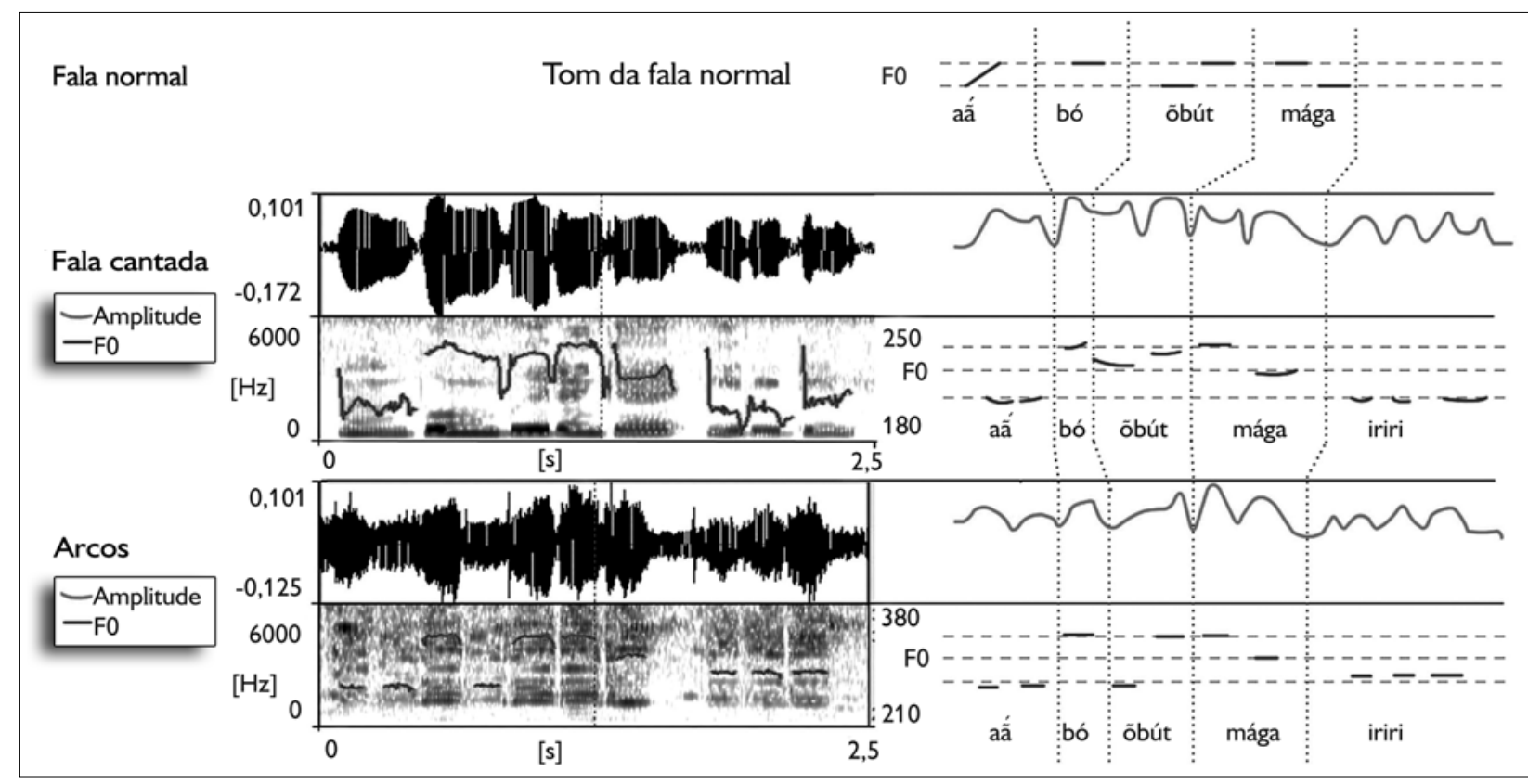

Figura 6. Extrato de arcos Iridináp.

um nível de amplitude relativamente estável e distinto dos outros, que corresponde à força do soprado aplicado pelo tocador na palheta para vibrar e produzir o som. Quanto menor a parte vibrante, maior a força necessária para fazê-la vibrar e mais alta a frequência do som que resulta da vibração.

\section{ALGUMAS CARACTERÍSTICAS FONÉTICAS E FONOLÓGICAS DA LÍNGUA GAVIÃO DE RONDÔNIA}

O conhecimento de alguns aspectos técnicos da língua dos Gavião é essencial para entendermos a relação entre a fala normal, o canto e a música instrumental associada a cada canto. Basicamente, todos os Gavião (população de aproximadamente 450 pessoas) falam a língua, que faz parte da família linguística Mondé, do tronco Tupí. Na fonologia, há quinze consoantes subjacentes, não muito diferentes das consoantes do português. Há somente cinco vogais contrastivas. A nasalização é contrastiva e se espalha à direita sob certas condições. Não há contrastes de acento (Moore, 1984).

A fonologia suprassegmental é muito mais complicada e diferente do português. Há contrastes entre tons altos e tons baixos e também entre vogais curtas e longas (Moore, 1984, 1999):

$\begin{array}{llll}\text { baixo } & \text { sep } & {[\mathrm{tse} \overline{\mathrm{p}}]} & \text { 'objeto parecido com folha' } \\ \text { alto } & \text { sép } & {[\mathrm{tse} \overline{\mathrm{p}}]} & \text { 'objeto parecido com um fio' } \\ \text { curto } & \text { aka } & {[\overline{\mathrm{k} k \bar{a}}]} & \text { 'matar' } \\ \text { longo } & \text { aa-kaa } & {[\overline{\mathrm{a}: \mathrm{k} \overline{\mathrm{a}}]}} & \text { 'vai' }\end{array}$

Em termos teóricos, os tons se comportam como autossegmentos e, por meio de processos de fusão de sílabas e ligação de tons baixos flutuantes, tons curvados são produzidos:

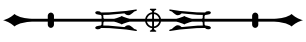




\begin{tabular}{|c|c|c|c|}
\hline subindo & ãá & $\widehat{\text { [ã:] }}$ & 'este' \\
\hline descendo & kît & [ki:t] & 'branco' \\
\hline subindo-descendo & pêèp & {$[\widehat{p e: p}]$} & reto' \\
\hline
\end{tabular}

Outra complicação é a de que certas sílabas provocam uma queda no nível de tons altos, que estão imediatamente adjacentes, até um nível médio. Nestes casos, o registro do resto do enunciado também cai. $\bigcirc$ fenômeno, chamado de passo descendente (downstep), é bem conhecido na África. Falantes de línguas europeias geralmente têm muita dificuldade em ouvir o tom e o prolongamento, uma vez que não são usualmente contrastivos nessas línguas. Todavia, os Gavião ouvem facilmente o tom e o prolongamento, que têm muito peso contrastivo na sua língua. Esses traços fonológicos são a base principal da fala assoviada dos Gavião e também da semelhança icônica entre fala, cantos e música instrumental.

\section{UMA CORRESPONDÊNCIA SISTEMÁTICA ENTRE TONS FONOLÓGICOS E NOTAS DE MÚSICA}

$\mathrm{Na}$ fala, existe uma distinção entre a frequência fundamental (FO) - que corresponde à vibração das cordas vocais e carrega a prosódia suprassegmental (incluindo o tom lexical no caso de línguas tonais) - e as suas ressonâncias harmônicas no trato vocal, que definem a qualidade das vogais e das consoantes. Já vimos que uma distinção entre timbre e F0 existe também na acústica dos instrumentos. Na base desse paralelo, uma das semelhanças mais notáveis observadas entre a música tocada pelos instrumentos Kotiráp, Totoráp, Iridináp e a fala normal é a correspondência sílaba por sílaba entre o tom respectivo das duas formas.

As variações de F0 das notas musicais correspondem diretamente às variações de F0 das letras do canto associado (ver Figuras 4, 5 e 6), que seguem também as variações de F0 do tom lexical da fala normal. Até o fenômeno complexo do passo descendente da fonologia Gavião é reproduzido pelas notas (como exemplificado na Figura 4 para Kotiráp, após 'kîi' de 'Kî káre béá', e na Figura 7 para Totoráp, após ‘léèy' de 'coliléèy mága').

Segundo o levantamento da literatura sobre fala instrumental feito por Bagemihl (1988) e os resultados publicados mais recentemente sobre o mesmo assunto (Zemp, 2004), o fenômeno de passo descendente nunca foi notado em nenhuma outra forma instrumental do mundo até agora. Nesse sentido, a análise dos instrumentos 'cantantes' Gavião representa uma contribuição importante para a teorização geral dos princípios de imitação instrumental da fala.

Outro aspecto importante da semelhança entre fala normal e música reside na duração das sílabas e das notas correspondentes: as vogais prolongadas são realizadas com sons prolongados nos instrumentos musicais, respeitando as distinções de quantidade da fonologia Gavião (como mostrado, por exemplo, na Figura 5). Com os arcos Iridináp, uma vogal prolongada às vezes é tocada com duas notas sucessíveis (veja, por exemplo, as duas primeiras notas da Figura 6).

Finalmente, a natureza fonética e fonológica da relação de iconicidade que existe entre as letras das canções e a música tocada com Totoráp, Kotiráp e Iridináp é simplesmente baseada na associação cognitiva entre, de um lado, o tom e prolongamento vocálico da língua e, de outro, as notas tocadas com instrumentos musicais. Essa associação é transparente e direta porque, como mostrado nos parágrafos precedentes, os dois dependem da frequência fundamental do sinal e rendem as mesmas melodias e os mesmos ritmos de frases. 


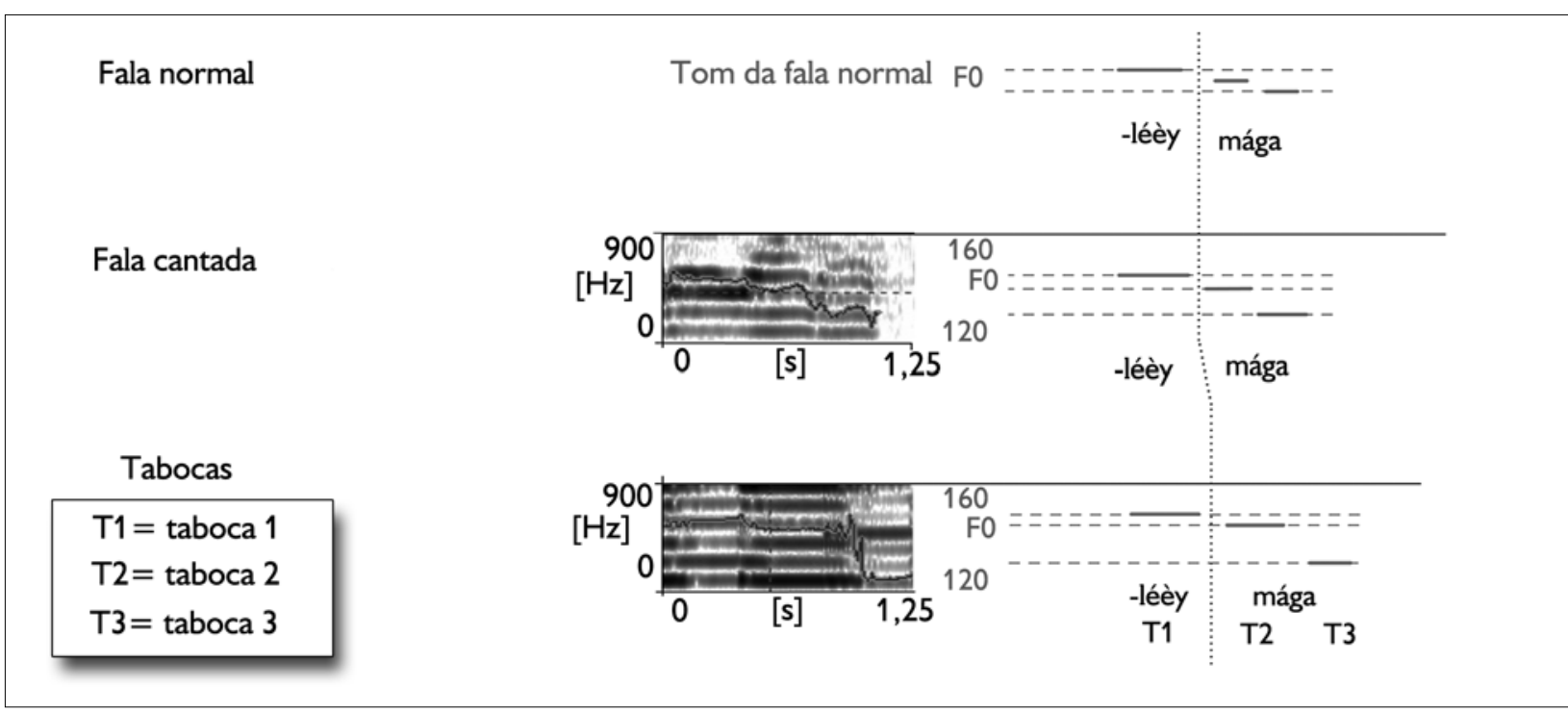

Figura 7. A regra tonal de passo descendente em Totoráp, extrato da frase 'coliléèy mága sết sết'.

Por outro lado, a maioria das diferenças observadas entre a forma instrumental e a forma normal da fala ocorre devido a efeitos estéticos do estilo cantado da fala, como mudanças de registro de voz, repetições de sílabas ou palavras (ver o tópico sobre "Algumas particularidades estéticas"), ou o uso de formas arcaicas das palavras que não existem mais na forma normal (ver o tópico seguinte, "Formas arcaicas"). Há também uma diferença importante que é ligada à dificuldade de produzir modulações de frequência com os instrumentos, uma vez que eles foram ajustados para tocar notas discretas. Por isso, as modulações de frequência - que são comuns entre dois tons consecutivos, produzindo tons curvados na fala normal Gavião - quase não são emuladas na forma instrumental, nem na forma cantada associada (fato mais surpreendente) (ver tópico sobre "Adaptação do modo cantado aos instrumentos").

\section{FORMAS ARCAICAS}

É interessante observar quais são as diferenças entre as formas arcaicas (marcadas em itálico nos textos em "Repertório e alguns exemplos de canções") e as modernas. Na frase apresentada na Figura 4, por exemplo, aparece um verbo 'bósara', que não existe na fala normal dos Gavião. Inesperadamente, a frase na Figura 6 contém a forma 'õbút' '1s-coisa+DIM', que retém o prefixo 'õ-'. Na evolução das línguas da família Mondé, este prefixo desapareceu há algum tempo em Gavião e Zoró, persistindo em Suruí e sendo opcional em Aruá. Então, uma das diferenças nas formas arcaicas comuns consiste no léxico e outra, nos processos morfológicos.

\section{ADAPTAÇÃO DO MODO CANTADO AOS INSTRUMENTOS}

As formas cantadas correspondentes às melodias tocadas com Totoráp, Kotiráp e Iridináp têm particularidades acústicas indicando que elas foram padronizadas pelos Gavião para serem tocadas nos instrumentos. As principais evidências que convergem para apoiar essa observação são as seguintes:

\footnotetext{
8 Dimensional.
}

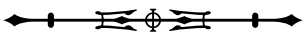


- Em princípio, a fala cantada não tem limitação na modulação da frequência fundamental. Por exemplo, existem, na cultura Gavião, gêneros de canções, como as do pajé ou as de festa, que não são ligados à prática de um instrumento musical e que usam a modulação do FO. Ao contrário, os tons das formas cantadas de canções de Totoráp, Kotiráp e Iridináp são realizados sem contornos (modulações) intertonais, de acordo com os limites dos instrumentos.

- Um segundo aspecto é que a forma cantada é adaptada ao número definido de notas diferentes de cada instrumento, como ilustrado nas Figuras 4, 5 e 6 (três notas para os instrumentos Totoráp e Iridináp e quatro notas para Kotiráp). No caso do Totoráp, como cada tocador representa uma parte do instrumento e executa somente uma nota, este também influencia a melodia, com a finalidade de que haja a participação de todos a cada frase tocada (Figuras 5, 7 e 8).

\section{ALGUMAS PARTICULARIDADES ESTÉTICAS}

Primeiramente, como todas as classes de cantos amazônicos, as músicas tocadas com os três instrumentos analisados usam vários tipos de repetição:

- repetição de toda uma frase (ver letras de música em "Repertório e alguns exemplos de canções");

- repetição de uma parte de uma frase, como em 'ikábiit ábi ká bi ká', em 'zólốp tî̀ zólốp tîi', ou em 'zérék kît zérék kît' (ver ilustração na Figura 8).

Uma técnica bastante comum é também a mudança de registro de voz:

- no meio de cada verso de música da flauta Kotiráp (Figura 4);

- entre repetições de uma mesma frase ou de uma parte da frase, no caso dos instrumentos Totoráp e Iridináp (ver também na ilustração da Figura 8, para o Totoráp).

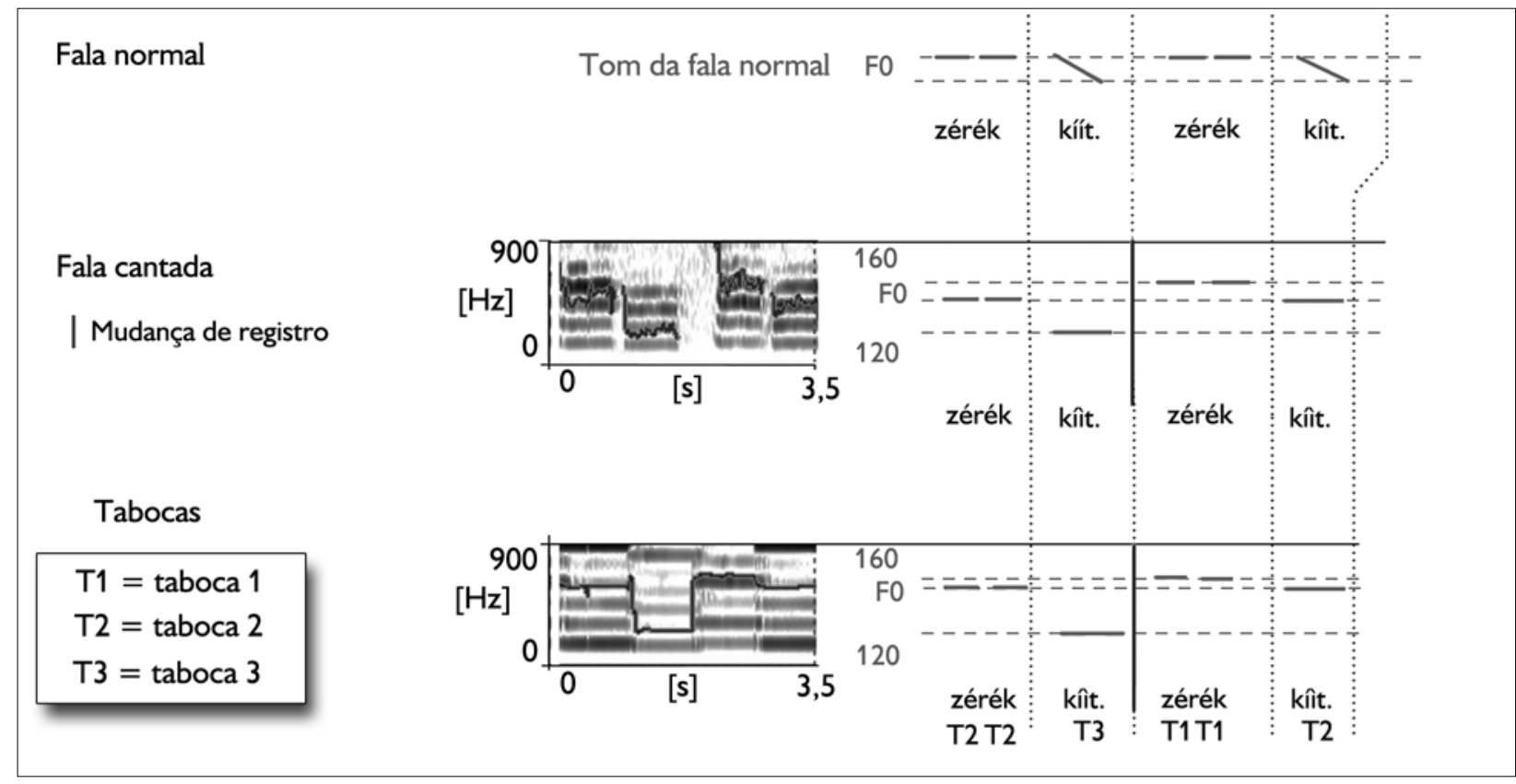

Figura 8. Repetição e mudança de registro de voz em Totoráp, extrato da frase 'zérék kît zérék kît máà'.

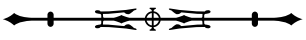




\section{CONCLUSÃO}

Os instrumentos cantantes Gavião, além de constituírem um patrimônio sociocultural importante e ameaçado de extinção, representam um fenômeno na interface entre língua e música. Na Amazônia, esse tipo de prática ainda é pouco conhecido por linguistas e musicólogos porque fica às margens das duas disciplinas. No presente artigo, mostramos as etapas principais de nossa metodologia para documentá-lo e estudá-lo.

O trabalho colaborativo com a comunidade foi bem aceito, especialmente entre os tocadores, que viram os seus conhecimentos tradicionais prestigiados; entre os jovens, que gravaram sons e vídeos e seguiram o processo de edição de DVDs; e entre as crianças, que aprenderam canções antigas. Foi também a ocasião de interagir com professores indígenas de escolas sobre o tom na sua língua. Os Gavião sabem que as canções tocadas com instrumentos musicais têm a particularidade rara de imitar a voz cantada e têm certo orgulho da sua capacidade de imitar traços linguísticos com sons musicais.

As perspectivas analíticas são múltiplas e pluridisciplinares. Assim, mostramos que as técnicas de análise linguística e de acústica permitem explicar, em detalhes, a natureza da relação música-língua nos instrumentos Totoráp, Iridináp e Kotiráp, na qual o tom lexical e o prolongamento vocálico constituem traços fundamentais. Essa especificidade vem do fato de que o tom linguístico é importante em uma língua tonal para o entendimento do significado das palavras das canções (bem mais que em uma língua sem tom, como o português). Outro aspecto importante dessa relação consiste no fato de as canções associadas às melodias instrumentais de Totoráp, Iridináp e Kotiráp conformarem-se a particularidades acústicas de cada instrumento. Isso mostra a influência dos limites acústicos dos instrumentos (número de notas mais discretas possíveis ou a quase impossibilidade de modular as frequências das notas) e de certas exigências no modo de tocá-los (como no caso das tabocas Totoráp, que precisam de coordenação e da participação de três pessoas).

A adaptação dos toques às exigências tonais da língua, bem como aos limites acústicos dos instrumentos, resulta em uma posição espeć́fica da fala cantada instrumental na escala dos diferentes estilos de fala Gavião (como ilustrado na Tabela 2).

Além da idade média dos bons tocadores, vários aspectos linguísticos convergem para mostrar a antiguidade do fenômeno. Assim, observamos formas arcaicas de palavras Gavião nas letras dos cantos associados às melodias tocadas, principalmente no nível do vocabulário e da morfologia. Interessantemente, não observamos índices de mudança diacrônica na fonologia das letras de canções analisadas.

Tabela 2. Adaptação do tom lexical a diferentes estilos de fala Gavião.

\begin{tabular}{c|c}
\hline Tipo de fala Gavião & Características linguísticas do tom \\
\hline Fala normal & Tons planos e curvados, prolongamentos vocálicos \\
\hline Fala assoviada & Tons planos e curvados, prolongamentos vocálicos \\
\hline $\begin{array}{c}\text { Canções associadas a } \\
\text { instrumentos }\end{array}$ & $\begin{array}{c}\text { Tons planos (somente), prolongamentos vocálicos e alterações estéticas que não têm } \\
\text { cedência no sistema tonal (mudanças simples de registro de voz e repetições) }\end{array}$ \\
\hline Instrumentos cantantes & $\begin{array}{c}\text { Tons planos (somente), prolongamentos vocálicos e alterações estéticas que não têm } \\
\text { cedência no sistema tonal (mudanças simples de registro de voz e repetições) }\end{array}$ \\
\hline
\end{tabular}

\footnotetext{
9 Existem vários gêneros de canções que não são ligadas a instrumentos musicais, onde as frequentes mudanças de registro de voz têm precedência nos tons fonológicos. Em consequência, elas seguem padrões melódicos diferentes de canções associadas aos instrumentos Kotiráp, Totoráp e Iridináp. Consultar MEYER, Julien; DENTEL, Laure; SEBIROP GAVIÃO, Xipiabit. "Canções Gavião". Belém: Museu Paraense Emílio Goeldi, 2010 (vídeo de documentação).
}

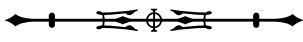


A partir dessas observações, elaboramos duas hipóteses: primeiro, é possível que as canções com formas arcaicas tenham sido compostas há dois séculos ou mais e foram mantidas na sua forma inicial. Segundo, é também possível que exista um sistema poético de composição musical característico desses instrumentos, capaz de produzir formas arcaicas, sendo conhecido pelos bons tocadores. O próximo passo será investigar a possível existência de formas arcaicas em músicas, de outros gêneros, de composição recente. Para esclarecer esses pontos, é preciso continuar a documentação e a colaboração com os Gavião e outros povos da família de línguas Mondé (Cinta Larga, Zoró, Aruá, Suruí) para estender o repertório de canções tocadas e comparar os fenômenos de maneira tipológica.

\section{AGRADECIMENTOS}

Ao povo Gavião de Rondônia; ao Endangered Language Documentation Programme-ELDP (The School of Oriental and African Studies-SOAS, University of London, projeto IPF0136); ao Conselho Nacional de Desenvolvimento Científico e Tecnológico (CNPq), pela Bolsa de Pós-Doutorado Júnior n. 159747/2010-4 e autorização de Expedição Científica n. EX032/08-CR; e à Fundação Nacional do índio (FUNAI), em Brasília e em Ji-Paraná.

\section{REFERÊNCIAS}

CARRINGTON, J. F. Talking drums of Africa. London: Carey-Kingstate Press, 1949.

CATLIN, Ami. Speech Surrogate Systems of the Hmong: from singing voices to talking reeds. In: DOWNING, Bruce T.; OLNEY, Douglas P. (Eds.). The Hmong in the West: observations and reports. Minneapolis: University of Minnesota, 1982. p. 170-197.

BAGEMIHL, Bruce. Alternate phonologies and morphologies. 1988. Tese (Doutorado em Linguística) - University of British Columbia, Vancouver, 1988.

ERMEL, Priscilla Barrak. L’Arc et la Lire: proposition d'un narratif visuel et sonore. Paris: Collège Iconique de l'Institut National de l'Audiovisuel (INA), 2004.

ERMEL, Priscilla Barrak. O arco e a lira. São Paulo: Laboratório de Som e Imagem em Antropologia, 2001.

EVERETT, Daniel. A língua Pirahã e a Teoria da Sintaxe: descrição, perspectivas e teoria. 1983. Tese (Doutorado em Linguística) - Universidade Estadual de Campinas, Campinas, 1983.

FRANCHETTO, Bruna; MONTAGNANI, Tommasso. Flutes des hommes, chant des femmes. Images et relations sonores chez les Kuikuro du haut Xingu. Gradhiva, v. 13, p. 94-111, 2011.

HILL, Jonathan. Keepers of the sacred chants: the poetics of ritual power in an Amazonian society. Tucson: The University of Arizona Press, 1993.

IZIKOVITZ, Karl Gustav. Idiophones. In: IZIKOVITZ, Karl Gustav. Musical and other sound instruments of the South American Indians: a comparative ethnographical study. Göteborg: Elanders Boktryckeri Aktiebolag, 1935. p. 7-33.

LOCKE, David; AGBELI, Godwin. Drum language in Adzogbo. The Black Perspective in Music, v. 9, n. 1, p. 25-50, 1981.

MEYER, Julien. Acoustic features and perceptive cues of songs and dialogues in whistled speech: convergences with sung speech. In: INTERNATIONAL SYMPOSIUM ON MUSICAL ACOUSTICS, 19., 2007, Barcelona. Proceedings... Barcelona: ISMA, 2007.

MEYER, Julien; DENTEL, Laure; SEIFART, Frank. A methodology for the study of rhythm in drummed forms of languages application to Bora Manguaré of Amazon. In: ANNUAL CONFERENCE OF THE INTERNATIONAL SPEECH COMMUNICATION ASSOCIATION, 13. Portland, 2012. Proceedings... Portland: Center for Spoken Language Understanding, 2012. p. 686-690.

MINDLIN, Betty; TSORABA, Digüt; SEBIROP, Catarino. Couro dos espíritos: namoro, pajés e cura entre os índios Gavião-Ikolen de Rondônia. São Paulo: Senac, Terceiro Nome, 2001.

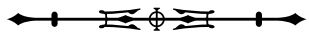


MOORE, Denny. Tonal System of the Gavião Language of Rondônia, Brazil, in Tupian perspective. In: SHIGEKI, Kaji (Org.). CrossLinguistic studies of tonal phenomena, tonogenesis, typology, and related topics. Tokyo: ILCAA/Tokyo University of Foreign Studies, 1999. p. 297-310.

MOORE, Denny. Syntax of the language of the Gavião Indians of Rondônia (Brazil). 1984. Tese (Doutorado em Antropologia) - City University of New York, Nova Iorque, 1984.

NILES, Don. Introduction. Kulele: Occasional Papers on Pacific Music and Dance, v. 4, p. 1-50, 2010.

NKETIA, J. H. K. Surrogate languages of Africa. In: SEBEOK, Thomas A.; UMIKER-SEBEOK, Donna Jean (Orgs.). Speech Surrogates: drum and whistle systems. La Hague and Paris: Mouton, 1976. p. 825-864.

POSS, Nick. The communication of verbal content on the Hmong Raj: an ethnographic analysis of performance practice. 2005. Dissertação (Mestrado em Etnomusicologia) - Ohio State University, Ohio, 2005.

RISSET, Jean Claude. Sur certains aspects fonctionnels de l'audition. Annales des Télécommunications, v. 23, n. 3, p. 91-120, 1968.

SCHOUTEN, J. F.; RITSMA, R. J.; CARDOZO, B. I. Pitch of the residue. Journal of the Acoustic Society of America, v. 34, p. 14181424, 1962.

SCHWARTZ, David A.; PURVES, Dale. Pitch is determined by naturally occurring periodic sounds. Hearing Research, v. 194, n. 1-2, p. 31-46, 2004

SEBEOK, Theodore; UMIKER-SEBEOK, Donna Jean. Speech Surrogates: drum and whistle systems. La Hague and Paris: Mouton, 1976.

STERN, Theodore. Drum and whistle languages: an analysis of speech surrogates. American Anthropologist, v. 59, n. 3, p. 487-506, 1957.

THIESEN, Wesley. The Bora signal drums. Lore, n. 19, p. 101-103, 1969.

WHIFFEN, Thomas. The North-West Amazons: notes of some months spent among cannibal tribes. New York: Duffield and Co., 1915. ZEMP, Hugo. Paroles de balafons. L'Homme, v. 171-172, p. 313-332, 2004.

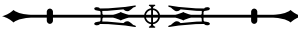

